\title{
Using of Tamarind and Vanilla Essential Oils for the Management of Brown Rot Disease of Potato
}

Moussa, Z. ${ }^{1}$; Eman Z. Goma ${ }^{2}$; Ehsan M. M. Rashad ${ }^{3}$ and E. A. Salem ${ }^{4}$

${ }^{1}$ Bacterial Diseases Research Dept., Plant Pathology Research Institute, Agricultural Research Center, Giza, Egypt.

${ }^{2}$ Biological and Geological Science Dept., Faculty of Education, Ain Shams University, Cairo, Egypt.

${ }^{3}$ Microbiology Activity Unit, Microbiology Dept., Soils, Water and Environment Research Institute, Agricultural Research Center, Giza, Egypt,

${ }^{4}$ Food Irradiation Dept., National Center for Radiation Research and Technology, Atomic Energy Authority, Cairo, Egypt

Corresponding author: Moussa, Z.: Bacterial Diseases Research Dept., Plant Pathology Research

Institute, Agricultural Research Center, Giza, Egypt - e.mail: zeiadmoussa@gmail.com

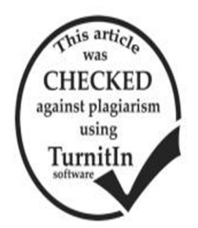

\section{ABSTRACT}

The hazard of chemical pesticides on the environment is a worldwide problem. Finding ecofriendly alternatives to chemical pesticides is a recent trend in agricultural research, one of the best choices is essential oils (EOs). This study aims to manage brown rot disease of potato using EOs. In vitro, Seven of 16 EOs inhibited Ralstonia solanacearum. The minimal inhibitory concentration (MIC) value was determined on $R$. solanacearum growth, tamarind and vanilla EOs had the lowest MIC (1\%). Gas Chromatography-Mass Spectrometry analysis indicated that the main components of tamarind EO (TEO) and vanilla EO (VEO) are propylene glycol (50.97 \%) and vanillin $(40.78 \%)$, respectively. TEO had a stronger bactericidal effect than VEO when $R$. solanacearum incubated in a solution of MIC of both EOs. In the pots experiment, soaking potato slices (spunta cultivar) in 1\% of each of TEO and VEO for 30 minutes significantly improved peroxidase, polyphenol oxidase, chlorophylls and carotenoids, as well as, increased the plant height after 70 days of planting in comparison with the control treatment. Both EOs significantly decreased the disease rating from 4.2 in control treatment to 1.6 (TEO) and 2.2 (VEO). In addition to marked increments up to $36.11 \%$ (TEO) and $32.52 \%$ (VEO) in fresh tubers weight. After 60 days of tubers storage at room temperature, the two EOs decreased the infected tubers by $69.05 \%$ (TEO) and $47.17 \%$ (VEO). Generally, TEO showed better results than VEO. The growth inhibition of $R$. solanacearum and enhancement of physiological characters and yield of potato, encouraging the use of these two uncommon EOs as effective tools to manage brown rot disease of potato.

Keywords: Ralstonia solanacearum, Inhibition, Bactericidal effect, Pot Experiment, Yield, Physiological characters.

\section{INTRODUCTION}

Brown rot (or bacterial wilt) disease of potato is one of the world's most devastating disease observed in most potato-producing areas of the world. The causal bacterial pathogen is called Ralstonia solanacearum that has a wide host range, it can infect plants belonging to 54 families; more than 450 plant species. It has high persistence and unavailable resistant crop varieties (Patil et al., 2017).

The chemical pesticides cause pollution that leads to hazards for the environment and human beings. So, researchers try to find safe ecofriendly tools to fight different plant pest and diseases. Essential oils are tools from these tools (Pavela and Benelli, 2016). Different methods of control of brown rot disease of potato, such as physical, cultural, biological, chemical, and integrated management were investigated (Yuliar et. al., 2015). Essential oils (EOs) are promising environmentally friendly tools in the management of $R$. solanacearum (Vu et. al, 2017).

The EOs are complex, volatile, secondary metabolites. These natural compounds are synthesized by different parts of aromatic plants. They have inhibitory effect against bacteria, fungi, (Miller et al. 2015) and viruses (Sánchez, and Aznar 2015) Furthermore, they have insecticidal (Pavela and Benelli, 2016) and nematocidal effect (Avato et al., 2017), in addition to the pharmaceutical, medicinal and cosmetic applications (Bakkali et al., 2008).

The EOs were used as effective tools in the management of soil born plant pathogen (Mihajlović et al., 2017). Moreover, the EOs are considered a new horizon to fight the bacterial antibiotic resistance (Yap et al., 2014).

Oboo et al. (2014) revealed that the EOs of Tarchonanthus camphorates (Camphor brush), Ocimum suave (Cambodia) and Lippie javanica (Sage brush) significantly reduced the bacterial wilt disease of potato.
$\mathrm{Li}$ and $\mathrm{Yu}$ (2015) reported that the EO obtained from the leaves of Macleaya cordata $\mathrm{R}$. Br. inhibited the growth of $R$. solanacearum. They showed that their EO increased the permeability of $R$. solanacearum cell membrane causing leakage of electrolytes, the losses of reducing sugar and proteins and change in the cell morphology leading to the death of bacteria.

The EOs enhance the physiological characters and increase the systemic induced resistance of plants and therefore increase the plant defense against pathogens. The EOs increase induced resistance of plants against bacterial pathogens (Lucas et al., 2012) and fungal pathogens (Vergnes et al., 2014).

The chemical components of the EOs vary from plant to another. Moreover, they vary in the same plant according to the effect of different factors that include the soil conditions, seasonal variation (humidity, temperature, rain, etc.), the age of the plant, the part of the plant and the method of extraction (Evergetis et al., 2016). The EOs are very complex natural compounds that contain different volatile components at different concentrations. They have two or three main components at concentrations (20 to 70\%) in comparing with others existing in trace concentrations. The EOs have different biological effects. The different components of the EOs have a synergistic effect. However, it is probable that the activity of the main components is modified by other minor molecules (Bakkali et al., 2008).

Pino et al. (2004) found that the major volatile constituents of tamarind (Tamarindus indica L.) fruits were 2-phenylacetaldehyde, 2-furfral and hexadecenoic acid. While Escalona-Arranz et al. (2010) reported that the leaves extract of tamarind had antimicrobial activity and the main components of this extract were benzyl benzoate, limonene and hexadecanole. 
The main volatile components of vanilla (Vanilla planifolia) were vanillic acid $(4 \%-5 \%)$, 4-hydroxy benzaldehyde $(6 \%-9 \%)$ and vanillin $(85 \%-87 \%)$ (Takahashi et al., 2013). Vanilla EO (VEO) inhibited a soil-borne Gram-negative bacterium that is called Chromobacterium violaceum $\mathrm{CV} 026$ where it inhibited quorum-sensing genes expression of the Tn- 5 mutant (Choo et al., 2006). Also, in vitro, VEO had inhibitory effects against Escherichia coli, Streptococcus faecalis, Enterobacter aerogenes, Proteus aeruginosa and P. vulgaris (Subramanian et al., 2009).

This investigation aims to use some uncommon EOs in control of brown rot disease of potato. The Effect of the EOs on inhibition of $R$. solanacearum, as well as, minimal inhibitory concentration (MIC) values of the effective ones were investigated. The bactericidal effect of the most effective EOs on $R$. solanacearum was studied. Pots experiment was carried out to indicate the in vivo effectivity of the most effective EOs on the management of the studied disease and on potato plants.

\section{MATERIALS AND METHODS}

\section{Essential oils:}

The used 16 commercial EOs were obtained from Kheder El-Attar Academy, Cairo, Egypt. The tested EOs were: Tamarind (Tamarindus indica L.), Vanilla (Vanilla planifolia), Hyacinth (Hyacinthus orientalis), Prunus (Prunus domestica), Apple (Malus domestica), Jasmine (Jasminum sambac), Pineapple (Ananas comosus), Tea (Camellia sinensis), Thermos (Lupinus albus L.), Olive (Olea europaea L.), Visnaga (Ammi visnaga (L.) Lam.), Limon (Citrus $\times$ limon (L.) Burm.f.), Banana (Musa sp.), Juniper (Juniperus L.), Flax (Linum usitatissimum L.) and Castor (Ricinus communis).

Bacterial pathogen:

Virulent isolate of Ralstonia solanacearum (race 3 biovar 2) was obtained from the Bacterial Collection of Bacterial Diseases Research Department, Plant Pathology Research Institute, Agricultural Research Center, Giza, Egypt

Potato Tubers: Potato tubers (Spunta cultivar) was obtained from Nubaria district, Bahaira Government, Egypt.

Antibacterial activity:

The agar disc diffusion method was carried out according to Teixeira et al. (2013) to study the antibacterial effect of the EOs against $R$. solanacearum. A bacterial suspension of $R$. solanacearum was adjusted to $10^{8} \mathrm{CFU} /$ $\mathrm{mL}$ and spread onto nutrient glucose agar (NGA) plates. Plates were kept for drying. On the center of plate, sterilized filter paper discs ( $5 \mathrm{~mm}$; Whatman No. 1), that drenched with the individual EO, were placed. Negative controls were prepared with sterilized distilled water. Plates were staying at $4{ }^{\circ} \mathrm{C}$ for $2 \mathrm{~h}$ for permission the diffusion of EOs from the discs through the media. The incubation of these plates was carried out at $28^{\circ} \mathrm{C}$ for $48 \mathrm{~h}$. The inhibitory effect of tested EOs was assessed by measuring the radius of inhibition zone (if present). Three replicates were prepared for each tested EO.

Minimal inhibitory concentration (MIC) determination: EOs that gave the largest inhibition zones were selected to investigate their MICs. The MIC is the lowest concentration which inhibits microorganism's growth. The MICs for the selected EOs were determined by using agar dilution method (Balouiri et. al., 2016). A serial dilution of each EO (2, 1, 0.5 and $0.25 \%(\mathrm{v} / \mathrm{v})$, was prepared in molten NGA medium with $0.5 \%(\mathrm{v} / \mathrm{v})$, Tween- 80 was incorporated into the agar after autoclaving. Inoculation was carried out with streaking $R$. solanacearum by a sterilized loop from liquid culture $\left(10^{8} \mathrm{CFU} / \mathrm{ml} 48 \mathrm{~h}\right.$. old $)$ onto the prepared plates. Plates of NGA medium, with $0.5 \%(\mathrm{v} / \mathrm{v})$ Tween80 and without any EO, was used as a control treatment. The incubation of these plates was carried out for $48 \mathrm{~h}$. at $28{ }^{\circ} \mathrm{C}$. The EOs having the lowest MICs were selected for further studies.

Analysis of the selected essential oils:

The selected EO(s) were subjected to analysis by Gas Chromatography/ Mass Spectrometry (GC/MS) which was performed in Central Agricultural Pesticide Laboratory (CAPL), Dokki, Giza, Egypt. GC/MS was performed on an Agilent 6890 gas chromatograph equipped with an Agilent mass spectrometric detector, with a direct capillary interface and fused silica capillary column PAS-5 ms (30 mm X 0.25 um film thickness). The injection of samples was performed under the following conditions:

The carrier gas washes helium (approximately 1 $\mathrm{ml} / \mathrm{min}$., pulsed splitless mode). The injection size was 1.0 ul. The solvent delay was $3 \mathrm{~min}$. The mass spectrophotometric detector was operated in electron impact ionization mode an ion energy of 70 e.v. scanning from $\mathrm{m} / \mathrm{z} 50$ to 500 . The ion source temperature was 230 ${ }^{\circ} \mathrm{C}$ and the quadrupole 1 temperature was $150{ }^{\circ} \mathrm{C}$. The electron multiplier voltage (EM voltage) was maintained $1250 \mathrm{v}$ above autotuned. The instrument was manually tuned using perfluorotributyl amine (PFTBA). The GC temperature program was started at $50{ }^{\circ} \mathrm{C}$ for $3 \mathrm{~min}$. then elevated to $280{ }^{\circ} \mathrm{C}$ at a rate of $8^{\circ} \mathrm{C} / \mathrm{min}$. and $15 \mathrm{~min}$. hold at $280^{\circ} \mathrm{C}$ the injector temperature was set at $280^{\circ} \mathrm{C}$. Willy and Nist 05 mass spectral data base was used in the identification of the separated peaks.

Solubility test:

The solubility of the MIC of the selected EOs in water (without tween 80 ) was tested.

Bactericidal effect of the selected EOs:

The bactericidal effect of the selected EOs was investigated according to the method of Joray et al. (2011). The suspension of R. solanacearum was prepared with concentration about $10^{10} \mathrm{CFU} / \mathrm{ml}$. The control treatment was prepared by adding $10 \mathrm{ml}$ of the prepared bacterial suspension to $90 \mathrm{ml}$ of sterilized tap water (or with Tween 80). The treatments of selected EOs were prepared as aforementioned with control and adding each individual selected EO with concentration of its MIC. In an incubator shaker $\left(28{ }^{\circ} \mathrm{C}\right.$ and $\left.120 \mathrm{rpm} / \mathrm{min}\right)$, the flasks were incubated. At selected time intervals, the serial dilution was applied for samples of these treatments and plated onto NGA plates. The incubation of plates was performed at 28 ${ }^{\circ} \mathrm{C}$ for $48 \mathrm{~h}$. After incubation, colony forming units (CFU) were determined. The values of $\log \mathrm{CFU} / \mathrm{ml}$ were calculated.Five replicates were applied for each dilution.

Pots experiment:

The preparation of inoculum of bacterial pathogen ( $R$. solanacearum) was done by inoculating 
this pathogen in Nutrient Glucose Broth (NGB) and incubating in an incubator shaker for $48 \mathrm{~h}$. $\left(28^{\circ} \mathrm{C}\right.$ and $120 \mathrm{rpm})$. By centrifugation $(10000 \mathrm{rpm} / \mathrm{min}$ for 20 min.), bacteria were precipitated. In sterilized tap water, the precipitate was re-suspended. The bacterial suspension was adjusted to $10^{8} \mathrm{CFU} / \mathrm{ml}$ concentration.

This experiment was carried out during the period of 21 February 2016 to 31 May 2016 at an openair at Tag El-Ezz Agricultural Research Station, Dakahlia, Egypt. The plastic sacks (pots) $[35 \mathrm{~cm}$ diameter] were filled with $20 \mathrm{~kg}$ non-sterilized soil. The used soil was a mixture of clay and sand 1:1 (w: w). Each pot was irrigated by water. Pots were left to dry for $72 \mathrm{~h}$., then infestation was done by $100 \mathrm{ml}$ of $R$. solanacearum $\left(10^{8} \mathrm{CFU} / \mathrm{ml}\right)$ for each pot. For about 48 h. the pots were left to dry. The healthy potato tuber slices of similar size were soaked (for $30 \mathrm{~min}$.) in the selected EOs with concentration equal MIC of each selected EO. In each pot, two potato tuber slices were planted. After 40 days of planting, one plant from each pot was harvested for assessment of polyphenol oxidase and peroxidase enzymes in addition to total phenols. The other plant of each pot was harvested at the end of the experiment. The plant height was measured after 70 days of planting. In addition, for estimation of chlorophylls and carotenoids, leaves from the same locations in the stem of potato plants were taken. The disease rating was estimated. For each treatment, five replicates were prepared. The experiment was designed in a completely randomized block design.

Biochemical assessments:

The enzymatic activity of peroxidase and polyphenol oxidase were assessed by using a spectrophotometric method according to Seleim et al. (2104). Folin-Ciocalteu reagent method [as described by Blainski et al. (2013)] was used to estimate total phenolic contents of fresh leaves. Chlorophyll a, chlorophyll b, total chlorophyll, and carotenoids in potato leaves were estimated as described by Wellburn (1994).

Disease rating:

As the scale described by Kempe and Sequeira (1983), wilt symptoms were assessed, where, $(0=$ no symptoms, $1=$ up to $25 \%$ wilt, $2=26-50 \%$ wilt, $3=51-75$ $\%$ wilt, $4=76-99 \%$ of the foliage wilted and $5=$ dead plants. Each plant was examined, the disease rating was assessed, and the mean value for each treatment was calculated.

Tubers weight:

At the harvesting time, the tubers of each pot were weighted. The mean weight and the percentage in the increase of tubers weight were calculated.

The percentage of the increase of potato tubers weight $=[($ Tubers weight of treatment - tubers weight of control) / tubers weight of control] X100 Infected tubers percentage:

Potato tubers were kept at room temperature for 6 weeks to help the appearance of latent infection, then, symptoms were clearly detected (Graham et al., 1979). Potato tubers were cut - after the storage period - to examine the existence of the disease symptoms. The infected tubers number was recorded. The percentage of the infected tubers was determined. The decrease of the percentage of infected tubers was calculated as the following:
The decrease in infected tubers $\%=[$ Infected tubers $\%$ of control Infected tubers \% of treatment)/ infected tubers \% of control] X100 Statistical analysis:

statistical analysis by software packages CoStat (version 6.4, CoHort Software, U.S.A) was used. The one-way randomized blocks design was applied in pots experiment. Duncan's multiple range test was used to compare the means at probability $(\mathrm{P})$ value of $\leq 0.05$.

\section{RESULTS AND DISCUSSION}

Results in (Table 1) showed that from 16 EOs, seven EOs were effective in inhibition of the growth of $R$. solanacearum in vitro experiment. The other tested EOs did not effective against the growth of $R$. solanacearum. Tamarind EO (TEO) was the most effective one causing inhibition zone of $40 \mathrm{~mm}$ diameter. Vanilla EO (VEO) caused inhibition zone of $36 \mathrm{~mm}$ diameter. On the other hand, jasmine EO had the smallest inhibition zone (11 $\mathrm{mm}$ diameter). This finding had the same harmony of the results of $\mathrm{Li}$ and $\mathrm{Yu}$ (2015) who found - in vitro - that the EO obtained from the leaves of Macleaya Cordata (Willd.) R. Br. inhibited $R$. solanacearum.

Also, results in Table (1) revealed the MIC values of TEO and VEO were $1 \%$. Hyacinth EO had MIC value $2 \%$. Prunus and apple EOs had MIC values more than $2 \%$. Therefore, TEO and VEO were selected for further investigations in this study. These results had the confirmation of those of Escalona-Arranz et al. (2010) who found that tamarind extract from leaves had antimicrobial activity. Choo et al. (2006) indicated that VEO inhibited quorum-sensing genes expression of the Tn-5 mutant of Chromobacterium violaceum CV026.

Table 1. The inhibitory effect of the tested EOs against R. Solanacearum and minimal inhibitory concentration of most effective oils.

\begin{tabular}{lccc}
\hline No. & $\begin{array}{c}\text { Essential } \\
\text { Oil }\end{array}$ & $\begin{array}{c}\text { Inhibition } \\
\text { zone diameter }(\mathbf{m m})\end{array}$ & $\begin{array}{c}\text { Minimal inhibitory } \\
\text { concentration (MIC) }\end{array}$ \\
\hline 1 & Tamarind & 40 & $1.0 \%$ \\
2 & Vanilla & 36 & $1.0 \%$ \\
3 & Hyacinth & 30 & $2 \%$ \\
4 & Prunus & 30 & $>2 \%$ \\
5 & Apple & 25 & $>2 \%$ \\
6 & Pineapple & 21 & N.D. \\
7 & Jasmine & 11 & N.D. \\
8 & Tea & 0 & N.D. \\
9 & Thermos & 0 & N.D. \\
10 & Olive & 0 & N.D. \\
11 & Visnaga & 0 & N.D. \\
12 & Limon & 0 & N.D. \\
13 & Banana & 0 & N.D. \\
14 & Juniper & 0 & N.D. \\
15 & Flax & 0 & N.D. \\
16 & Castor & 0 & N.D. \\
\hline
\end{tabular}

* The inhibition zone diameters were measured directly from the plate, the recorded numbers were the means of three replicates, 0 : No inhibition zone and N.D.: Not detected.

Data in Table (2) indicated the GC/MS of TEO and VEO. Data revealed that propylene glycol is the main component $(50.97 \%)$ of TEO and other components are Benzaldehyde $(39.70 \%)$, 4-[(dimethylamino) methyl]-2methoxyphenol $(6.92 \%)$ and $2(3 \mathrm{H})$-Furanone $(1.77 \%)$. The 
main component of VEO is vanillin $(40.78 \%)$ and the other components are $2(3 \mathrm{H})$-furanone $(21.75 \%)$, 3-ethoxy-4hydroxy-Benzaldehyde (19. $24 \%)$, acetic acid (10.43\%), benzyl alcohol, (5.26\%) and Vanillin propylene glycol acetal $(2.24 \%)$. GC/MS analysis of TEO disagrees with the results of volatile components of TEO obtained by Pino et al. (2004) and Escalona-Arranz et al. (2010). Li and Yu (2015) found that the chemical composition of EO of their study is different from the chemical composition of the same EO of the same plant. The differences of volatile components may be due to several reasons, such as, the part of the plant used for extraction, physiological age of the plant, method of extraction, environmental condition and the growing season ( $\mathrm{Li}$ and $\mathrm{Yu}, 2105)$.

Propylene glycol has bactericidal activity on the growth of $S$. mutans $E$. faecalis and $E$. coli (Nalawade et al., 2015). Moreover, "2 (3H)-Furanone" have antimicrobial activity against six types of bacteria and two types of fungi in vitro (Abou-Elmagd et al., 2015). Also, benzaldehyde has insecticidal, antimicrobial, and antioxidant activity (Ullah et al., 2015).

Vanillin has antibacterial activity against Listeria innocua, Lactobacillus plantarum and Escherichia coli acting as a membrane-active compound, resulting in the dissipation of ion gradients and the inhibition of respiration, the extent to which is species-specific. These effects initially do not stop the production of ATP Fitzgerald et al. (2004). Acetic acid has antimicrobial activity against different isolates of Staphylococcus aureus, Pseudomonas aeruginosa, Streptococcus pyogene and Proteus mirabilis (Thorp et al., 1998). Moreover, it inhibited the growth of Shigella species: S.dysenteriae, S. sonnei, S. boydii and S. flexneri, (In et al., 2013). Bjarnsholt et al. (2015) showed that acetic acid has antibiofilm properties.

Table 2. Gas Chromatography/ Mass Spectrometry (GC/MS) of TEO and VEO.

\begin{tabular}{lcc}
\hline $\begin{array}{l}\text { Essential } \\
\text { oil }\end{array}$ & Component & $\begin{array}{c}\text { Area } \\
\mathbf{\%}\end{array}$ \\
\hline \multirow{4}{*}{ TEO } & Propylene glycol & 50.97 \\
& 2 (3H)-Furanone & 1.77 \\
& Benzaldehyde & 39.70 \\
& 4-[(dimethylamino)methyl]-2- & 6.92 \\
\hline \multirow{4}{*}{ methoxyphenol } & 10.43 \\
& Acetic acid & 5.26 \\
& Benzyl alcohol & 21.75 \\
& 2(3H)-Furanone & 40.78 \\
& 2-ethoxy-4-hydroxy-Benzaldehyde & 19.24 \\
& Vanillin propylene glycol acetal & 2.24 \\
\hline
\end{tabular}

The test of the solubility of the two selected EOs in water without tween 80 indicated that these two EOs are soluble in water without tween 80 . Therefore, the following tests were carried out by dissolving these two EOs directly in water without tween 80 . Therefore, this solubility in water enhanced the antibacterial activity of these two EOs (Calo et al., 2015).

As shown in Fig. (1) the incubation of $R$. solanacearum with TEO and VEO at concentration of 1 $\%$ (MIC) led to significant decrements of bacterial count of $R$. solanacearum more than the control (incubation with sterilized tap water). TEO was more effective in decreasing the viable bacterial count of $R$. solanacearum than VEO. The decrease in the viable bacterial count of $R$. solanacearum that preserved in sterilized tap water is very low; Log CFU/ $\mathrm{ml}$ decreased from 9.876 to 9.140 after $24 \mathrm{~h}$. The reduction in the count of $R$. solanacearum that incubated with TEO was high till $3 \mathrm{~h}$. where the Log CFU/ml was decreased from 9.162 to 3.788 . While, after $3 \mathrm{~h}$., the decrease of the bacterial count is very low, where Log CFU/ $\mathrm{ml}$ was decreased from 3.788 after $3 \mathrm{~h}$. of incubation to 3.352 after $24 \mathrm{~h}$. of incubation. A similar trend was observed with VEO where the rate of decreasing of the bacterial count was high till $3 \mathrm{~h}$. and after $3 \mathrm{~h}$. the rate of decreasing of bacterial count till $24 \mathrm{~h}$. is very low. These results are in the same trend of $\mathrm{Li}$ and $\mathrm{Yu}$ (2015) who found that the count of $R$. solanacearum count was decreased when it incubated with the MIC of the EO from the leaves of Macleaya cordata $\mathrm{R}$. Br. The mode of action of the two selected EOs against $R$. solanacearum may be due increasing the permeability of bacterial cell membrane leading to leakage of electrolytes, the losses of reducing sugar and proteins and damage in the bacterial cells leading to death of bacteria and decreasing of the viable bacterial count according to the findings of $\mathrm{Li}$ and $\mathrm{Yu}$ (2015).

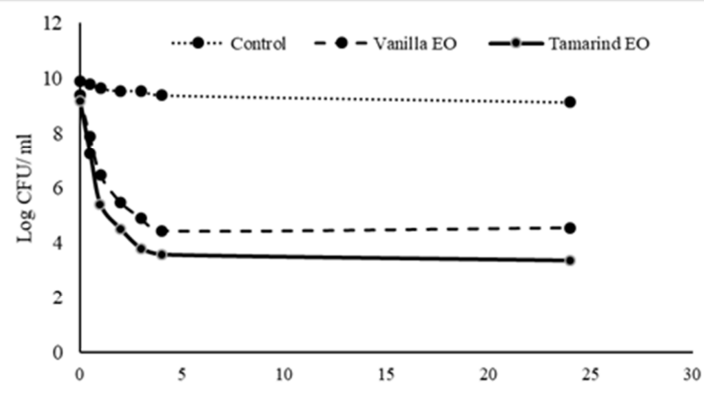

Fig. 1. Bactericidal effect of the two selected EOs on R. solanacearum

All recorded values are means of five replicates.

Data in Table (3) declared that the two selected EOs improved the productivity of enzymes that play an important role in inducing resistance and photo-synesthetic pigments. The two selected EOs led to significant increase in peroxidase (POD) activity, which increased from 12.00 Unit.min $^{-1} \cdot \mathrm{g}^{-1} \mathrm{FW}$ in control to 22.67 and 16 Unit.min $^{-1} \cdot \mathrm{g}^{-1}$ FW in TEO and VEO treatments, respectively. The polyphenol oxidase (PPO) increased from 5.33 Unit.min ${ }^{-1} \cdot \mathrm{g}^{-1}$ in control treatment to 13.33 and 6.67 Unit.min ${ }^{-1} \cdot \mathrm{g}^{-1}$ in the plants treated with TEO and VEO respectively where the last increase was non-significant. Furthermore, total phenols increased in plants treated with the two EOs from $27.84 \mathrm{mg}$ GAE/g FW to 53.89 and $38.53 \mathrm{mg} \mathrm{GAE} / \mathrm{g} \mathrm{FW}$ in TEO and VEO treatments, respectively. These physiological parameters reflecting the health condition of the plant. These results are confirmed with Vergnes et al. (2104) who found that the EOs increase induced resistance against the bacterial pathogen or the fungal pathogen. In this respect, Lamba et al. (2008) reported phenols accumulated rapidly of at the infection site, which limited or slowed the growth of the pathogen due to their antimicrobial and antioxidant action. The proposed mode of action for the pathogen defense role of PPO, include; (1) General toxicity to pathogens. (2) Alkylation causing redaction of bioavailability of cellular proteins to the pathogen. (3) A physical barrier to pathogens 
in the cell wall that is forming due to crosslinking of quinones with protein or other phenolics. (4) Quinone redox cycling, leading to $\mathrm{H}_{2} \mathrm{O}_{2}$ and other reactive oxygen species that are important factors in plant pathogen interactions and defense signaling (Raj et al., 2006). POD is an important factor in the integrated resistance response of plants to different of stresses due to the its important roles in the production of toxic secondary metabolites, in cell wall toughening and its simultaneous oxidant and antioxidant capabilities (Thakker et al., 2013).

The two EOs treatments led to significant increases in the photosynthetic pigments of potato leaves compared with the control (Table 3). Potato plants treated with TEO recorded the highest values in the content of $\mathrm{Chl} \mathrm{a,} \mathrm{b}$ and total Chl (1.225, 0.8923 and $2.0908 \mathrm{mg} / \mathrm{g} \mathrm{FW}$, respectively), followed by VEO (1.0720, 0.8658 and $1.9643 \mathrm{mg} / \mathrm{g} \mathrm{FW}$, respectively). The same trend was observed in carotenoids. Enhancement of the chlorophyll content is a parameter indicating improving the health condition of the plant, by enhancing the effectiveness of photosynthetic apparatus leading to enhancement in the disease resistance (Amaresh and Bhatt, 1998). Carotenoids are essential for plant life, during photosynthesis. Carotenoids are parts of a framework of protection of the photosynthetic apparatus against high light disorder (Lachman et. al., 2016).

Table 3. Physiological characteristics of potato as affected by the two EOs treatments in pots experiment

\begin{tabular}{|c|c|c|c|c|c|c|c|}
\hline \multirow[b]{2}{*}{ Treatment } & \multirow{2}{*}{$\begin{array}{c}\text { Peroxidase } \\
\left(\text { Unit.min }^{-1} \cdot \mathrm{g}^{-1} \mathrm{FW}\right)\end{array}$} & \multirow{2}{*}{$\begin{array}{c}\text { Polyphenol } \\
\text { oxidase } \\
\text { (Unit.min }{ }^{-1} \cdot \mathrm{g}^{-1} \mathrm{FW}\end{array}$} & \multirow{2}{*}{$\begin{array}{c}\text { Total } \\
\text { phenols } \\
\text { mgGAE } / \text { g FW)* }\end{array}$} & \multicolumn{4}{|c|}{ Photo-synesthetic pigments (mg/g FW) } \\
\hline & & & & $\begin{array}{c}\text { Chlorophyll } \\
\mathbf{a}\end{array}$ & $\begin{array}{c}\text { Chlorophyll } \\
\text { b }\end{array}$ & $\begin{array}{c}\text { Total } \\
\text { Chlorophyll }\end{array}$ & Carotenoids \\
\hline Control & $12.00 \mathrm{c}$ & $5.33 \mathrm{~b}$ & $27.84 \mathrm{c}$ & $0.9792 \mathrm{c}$ & $0.8100 \mathrm{c}$ & $1.7892 \mathrm{~b}$ & $0.5269 \mathrm{~b}$ \\
\hline Tamarind oil & $22.67 \mathrm{a}$ & $13.33 \mathrm{a}$ & $53.89 \mathrm{a}$ & $1.2250 \mathrm{a}$ & $0.8923 \mathrm{a}$ & $2.0908 \mathrm{a}$ & $0.6317 \mathrm{a}$ \\
\hline Vanilla oil & $16.00 \mathrm{~b}$ & $6.67 \mathrm{~b}$ & $38.53 \mathrm{~b}$ & $1.0720 \mathrm{~b}$ & $0.8658 \mathrm{~b}$ & $1.9643 \mathrm{a}$ & $0.6609 \mathrm{a}$ \\
\hline
\end{tabular}

*: milligram Gallic Acid equivalent (GAE)/ gram Fresh weight.

All recorded values are means of three replicates; means followed by the different letter within each column is significantly different using Duncan's Multiple Range Test at $P$ value of $\leq .0 .05$

As revealed in Fig. (2), the two selected EOs enhanced the growth of potato plants. The plant height after 70 days of planting was significantly increased in plants treated with EOs comparing with control. The plant height increased from $31.2 \mathrm{~cm}$ in the control to 43.2 and $41 \mathrm{~cm}$ in the plants treated with TEO and VEO, respectively. This improvement of vegetable growth may be due to the enhancement of physiological characters and the inhibitory effect of two EOs against the tested bacterial pathogen.

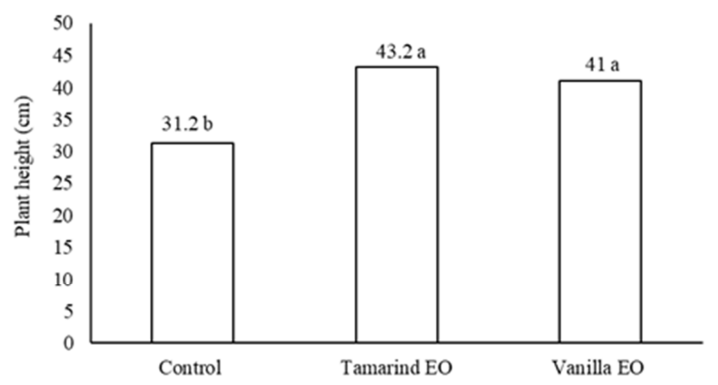

Fig. 2. Effect of the two selected EOs on plant height of potato pants after 70 days of planting.

Column scripted with different letter is significantly different using Duncan's Multiple Range Test at $P$ value of $\leq \mathbf{0 . 0 5}$.

Data illustrated in Fig. (3) indicated that disease rating of treated plants with the two selected EOs was significantly decreased than the corresponding value of the untreated plants. The disease rating decreased from 4.2 in the control to 1.6 and 2.2 in plants treated with TEO and VEO, respectively. These results had the confirmation of Oboo et al., (2014) who indicated that EOs decreased the disease incidence of bacterial wilt of potato. The decrease of disease rating may due to the inhibitory effect of the two EOs against the test bacterial pathogen and the increase of systemic induced resistance of potato plant.

Data illustrated in Fig. (4) showed that the tubers weight of the treated pots significantly increased compared with the control. The weight of tubers for each pot increased from $122.4 \mathrm{~g}$ in the control to 166.6 and $162.2 \mathrm{~g}$ in the plants treated with TEO and VEO respectively. The percentages of yield increase were $36.11 \%$ and $32.52 \%$ with TEO and VEO, respectively.

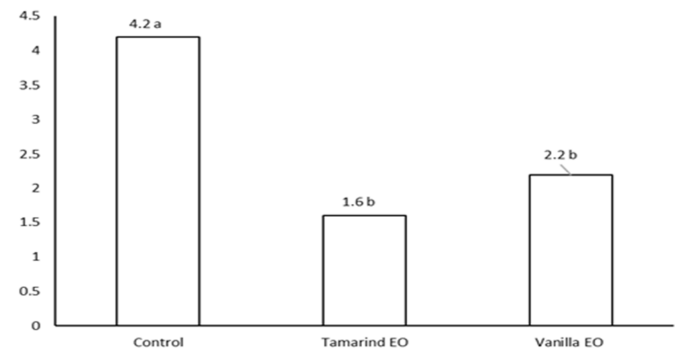

Fig. 3. Disease rating of potato plants in pots experiment Column scripted with different letter is significantly different using Duncan's Multiple Range Test at $P$ value of $\leq \mathbf{0 . 0 5}$. Disease rating scale: $0=$ no symptoms, $1=$ up to $25 \%$ wilt, $2=26-50 \%$ wilt, $3=51-75 \%$ wilt, $4=76-99 \%$ of the foliage wilted and $5=$ dead plants

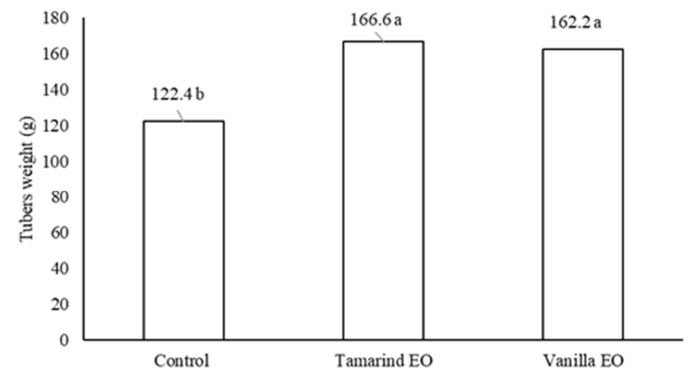

Fig. 4. Effect of the two selected EOs on tubers weights of potato tubers.

Column scripted with different letter is significantly different using Duncan's Multiple Range Test at $P$ value of $\leq 0.05$.

Data illustrated in Fig. (5) revealed that the infected tubers percentage of the two treatments of the used EOs after 60 days of storage at room temperature were significantly decreased. These percentage decreased from $88.33 \%$ in the control treatment to 27.33 and $46.33 \%$ with TEO and VEO treatment, respectively. While there was no significant difference between the value of this parameter with the treatments of the two EOs. So, the treatment of potato seeds 
with these two EOs decreased the infected tubers by percentage $69.05 \%$ for TEO and 47.17 for VEO. The increase in yield and decrease in potato infected tubers percentage may be because of these two EOs against the studied bacterial pathogen and their effect on other bacterial and fungal pathogens (Miller et al.,2016) and their insecticidal effect (Pavela and Benelli, 2016). EOs have nematocidal activity (Avato et al. 2017). In addition, this effect is a result of their enhancement of physiological characters of the plant and increase in the induced resistance.

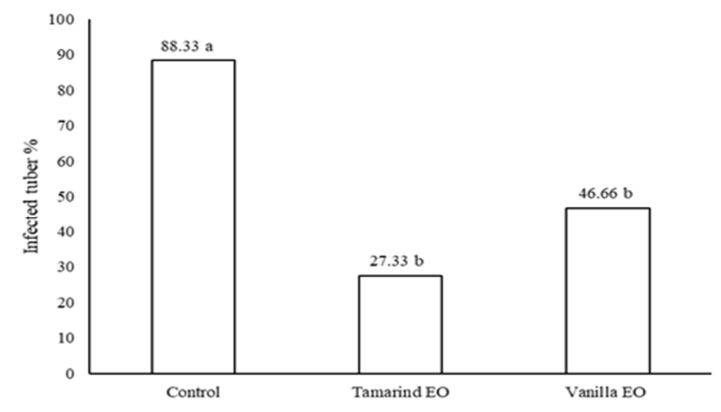

Fig. 5. Effect of the two selccted EOs on the infected tubers precntage after storage for 60 days at room temperature.

Column scripted with different letter is significantly different using Duncan's Multiple Range Test at $P$ value of $\leq \mathbf{0 . 0 5}$

\section{CONCLUSION}

Therefore, it could be concluded that TEO and VEO can be used to manage brown rot disease of potato. In vitro, they inhibited the growth of $R$. solanacearum. In pots experiment, they significantly decreased the disease rating and increased plant height during the vegetative growth. They enhanced the potato plants systemic induced resistance and improve their physiological characters. They significantly increased the fresh weight of potato tubers and significantly decreased the infected potato tubers.

\section{REFERENCES}

Abou-Elmagd, W. S., El-Ziaty, A. K. and A. A. Abdalha 2015. Ring transformation and antimicrobial activity of indolyl-substituted 2 (3H)-furanones. Heterocyclic Communications, 21(3), 179-185.

Amaresh, C. and R.K. Bhatt 1998. Biochemical and physiological response to salicylic acid in reaction to systemic acquired resistance. Photosynthetica, 35: 255258.

Avato, P., Laquale, S., Argentieri, M. P., Lamiri, A., Radicci, V. and T. D'Addabbo, 2017. Nematicidal activity of essential oils from aromatic plants of Morocco. J. Pest Sci., 90 (2), 711-722.

Bakkali, F.; Averbeck, S.; Averbeck, D., and M. Idaomar 2008. Biological effects of essential oils-a review. Food and Chem. Toxicol. 46 (2), 446-475.

Balouiri, M., Sadiki, M., and S. K. Ibnsouda 2016. Methods for in vitro evaluating antimicrobial activity: A review. J. Pharm. Analysis, 6 (2), 71-79.

Bjarnsholt, T., Alhede, M., Jensen, P. Ø., Nielsen, A. K., Johansen, H. K., Homøe, P., Høiby N., Givskov, M. and K. Kirketerp-Møller, 2015. Antibiofilm properties of acetic acid. Advances in Wound Care, 4 (7), 363-372.
Blainski, A., Lopes, G. C., and J. C. P. De Mello 2013 Application and analysis of the Folin Ciocalteu method for the determination of the total phenolic content from Limonium brasiliense L. Molecules, 18: 6852-6865.

Calo, J. R., Crandall, P. G., O’Bryan, C. A., and S. C. Ricke 2015. Essential oils as antimicrobials in food systems A review. Food Control, 54, 111-119.

Choo, J.H.; Rukayadi, Y. and J.K. Hwang 2006. Inhibition of bacterial quorum sensing by vanilla extract. Lett. Appl. Microbiol., 42, 637-641.

Escalona-Arranz, J. C.; Péres-Roses, R.; Urdaneta-Laffita, I.; Camacho-Pozo, M. I.; Rodríguez-Amado, J.; and I. Licea-Jiménez 2010. Antimicrobial activity of extracts from Tamarindus indica L. leaves. Pharmacognosy Magazine, 6 (23), 242 - 247.

Evergetis, E., Michaelakis, A., Papachristos, D. P., Badieritakis, E., Kapsaski-Kanelli, V. N., and S. A. Haroutounian 2016. Seasonal variation and bioactivity of the essential oils of two Juniperus species against Aedes (Stegomyia) albopictus (Skuse, 1894). Parasitol. Res., 115 (6), 2175-2183.

Fitzgerald, D.J.; Stratford, M.; Gasson, M.J.; Ueckert,J.; Bos, A. and A. Narbad 2004. Mode of antimicrobial action of vanillin against Escherichia coli, Lactobacillus plantarum and Listeria innocua. J. A. Microbiol., 97, 104-113.

Graham, J., Jones, D.A. and A.B. Loyd, 1979. Survival of Pseudomonas solanacereau race 3 in the Plant debris and in latent infected potato tubers. Phytopathol., 69:1100 - 1103.

In, Y. W., Kim, J. J., Kim, H. J. and S. W. Oh 2013. Antimicrobial activities of acetic acid, citric acid and lactic acid against Shigella species. J. Food Safety, 33(1), 79-85.

Joray, M.B.; Del Rollan, M.R.; Ruiz, G.M.; Palcios, S.M. and M.C. Carpinella 2011. Antibacterial activity of extracts from plants of central Argentina - isolation of an active principle from Achrocline satureioides. Planta Med. 77, $95-100$.

Kempe, J. and L. Sequeira 1983. Biological control of bacterial wilt of potatoes: Attempts to induce resistance by treating tubers with bacteria. Plant dis., 67(5): 499-503.

Lachman, J., Hamouz, K., Orsák, M., and Z. Kotíková, 2016. Carotenoids in potatoes - a short overview. Plant Soil Environ., 62:10, 474-481.

Lamba, P., Sharma, S., Munshi, G.D. and S.K. Munshi 2008. Biochemical changes in sunflower plants due to seed treatment/spray application with biocontrol agents. Phytoparasitica, 36: 388-399.

Li, C. M. and J. P. Yu 2015. Chemical composition, antimicrobial activity and mechanism of action of essential oil from the leaves of Macleaya Cordata (Willd.) R. Br. J. Food Safety, 35(2), 227-236.

Lucas, G. C., Alves, E., Pereira, R. B., Perina, F. J., and R. M. D. Souza 2012. Antibacterial activity of essential oils on Xanthomonas vesicatoria and control of bacterial spot in tomato. Pesquisa Agropecuária Brasileira, 47(3), 351-359.

Mihajlović, M.; Rekanović, E.; Hrustić, J., Grahovac, M. and B. Tanović 2017. Methods for management of soilborne plant pathogens. Pesticidi I Fitomedicina, 32(1), 9-24. 
Miller, A. B., Cates, R. G., Lawrence, M., Soria, J. A. F., Espinoza, L. V., Martinez, J. V. and D. A. Arbizú (2015). The antibacterial and antifungal activity of essential oils extracted from Guatemalan medicinal plants. Pharm. Biol., 53(4), 548-554.

Nalawade, T. M., Bhat, K. and S.H. Sogi 2015. Bactericidal activity of propylene glycol, glycerine, polyethylene glycol 400, and polyethylene glycol 1000 against selected microorganisms. J. Int. Soc. Prev. Community Dent. 5 (2):114-9.

Oboo, H., Muia, A. W., and Z. M. Kinyua 2014. Effect of selected essential oil plants on bacterial wilt disease development in potatoes. J. App. Biosci., 78 (1), 66666674.

Patil, V. U., V. Girimalla, V. Sagar, R. S. Chauhan and S. K. Chakrabarti. 2017. Genome sequencing of four strains of phytotypes I, II and IV of Ralstonia solanacearum that cause potato bacterial wilt in India. Barazil. J. Microbiol., 48, 193-195.

Pavela, R., and G. Benelli 2016. Essential oils as ecofriendly biopesticides? Challenges and constraints. Trends Plant Sci., 21(12), 1000-1007

Pino, J. A.; Marbot, R. and C. Vazquez 2004. Volatile components of tamarind (Tamarindus indica L.) grown in Cuba. J. Essential Oil Res., 16(4), 318-320.

Raj, S. N., Sarosh, B. R., and H. S. Shetty 2006. Induction and accumulation of polyphenol oxidase activities as implicated in development of resistance against pearl millet downy mildew disease. Functional Plant Biol., 33(6), $563-571$.

Sánchez, G., and R. Aznar 2015. Evaluation of natural compounds of plant origin for inactivation of enteric viruses. Food Environ. Virol., 7(2), 183-187.

Seleim, M. A., Abo-Elyousr, K. A., Mohamed, A. A. A. and H. A. Al-Marzoky, 2014. Peroxidase and polyphenoloxidase activities as biochemical markers for biocontrol efficacy in the control of tomato bacterial wilt. J. Plant Physiol. Pathol. 2: 1-4.

Subramanian, S.; Banu, H.H.; Bai, R.M.R. and R. Shanmugavalli 2009. Biochemical evaluation of antihyperglycemic and antioxidant nature of Psidium guajava leaves extract in streptozotocin-induced experimental diabetes in rats. Pharm. Biol., 47, 298 303.
Takahashi, M.; Inai, Y.; Miyazawa, N.; Kurobayashi, Y. and A. Fujita 2013. Identification of the Key Odorants in Tahitian Cured Vanilla Beans (Vanilla tahitensis) by GC-MS and an Aroma Extract Dilution Analysis. Biosci. Biotechnol. Biochem., 77, 601-605.

Teixeira, B., Marques, A., Ramos, C., Neng, N. R., Nogueira, J. M., Saraiva, J. A., and M. L. Nunes 2013. Chemical composition and antibacterial and antioxidant properties of commercial essential oils. Industrial Crops and Products, 43, 587-595.

Thakker, J. N., Patel, S., and P. C. Dhandhukia 2013. Induction of defense-related enzymes in banana plants: Effect of live and dead pathogenic strain of Fusarium oxysporum f. sp. cubense. ISRN Biotechnology, 1-6.

Thorp, M., Kruger, J., Oliver, S., Nilssen, E., and C. Prescott 1998. The antibacterial activity of acetic acid and Burow's solution as topical otological preparations. J. Laryngol. Otol., 112(10), 925-928.

Ullah, I., Khan, A. L., Ali, L., Khan, A. R., Waqas, M., Hussain, J., Lee, J.H. and J. H. Shin 2015. Benzaldehyde as an insecticidal, antimicrobial, and antioxidant compound produced by Photorhabdus temperata M1021. J. Microbiol., 53(2), 127-133.

Vergnes, S., Ladouce, N., Fournier, S., Ferhout, H., Attia, F., and B. Dumas 2014. Foliar treatments with Gaultheria procumbens essential oil induce defense responses and resistance against a fungal pathogen in Arabidopsis. Frontiers Plant Sc., 5: 1-8.

Vu, T. T., Choi, G. J., and J. C. Kim 2017. Plant-derived Antibacterial Metabolites Suppressing Tomato Bacterial Wilt Caused by Ralstonia solanacearum. Res. Plant Dis., 23(2), 89-98.

Wellburn, A. R. (1994). The spectral determination of chlorophylls a and b, as well as total carotenoids, using various solvents with spectrophotometers of different resolution. J. Plant Physiol., 144(3), 307-313.

Yap, P. S. X., Yiap, B. C., Ping, H. C., and S. H. E. Lim 2014. Essential oils, a new horizon in combating bacterial antibiotic resistance. Open Microbiol. J., 8, 6-14.

Yuliar, Nion, Y. A., and K. Toyota 2015. Recent trends in control methods for bacterial wilt diseases caused by Ralstonia solanacearum. Microbes and Environments, 30(1), 1-11.

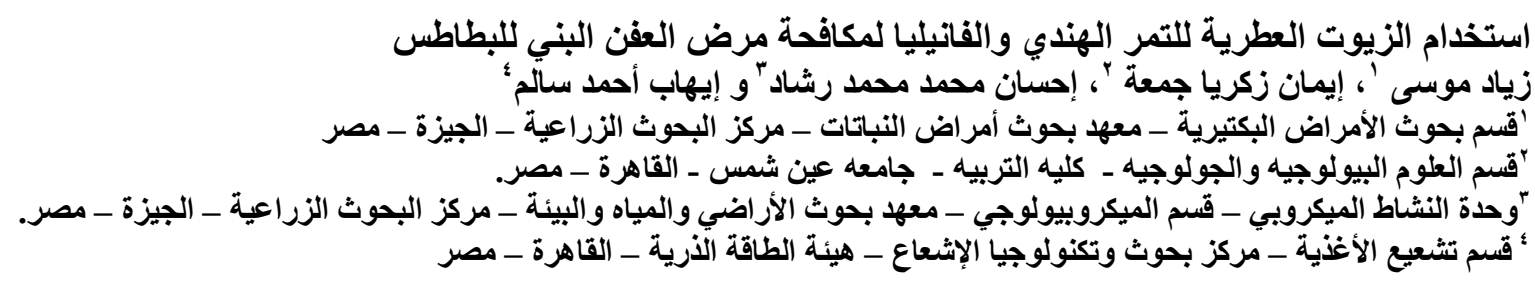

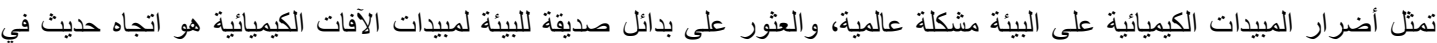

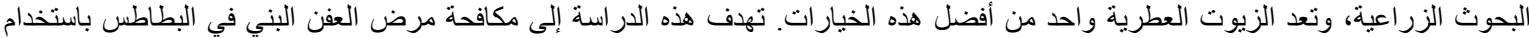

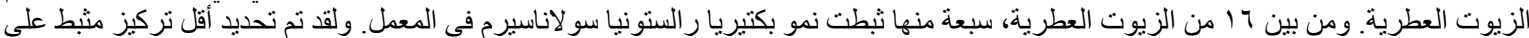

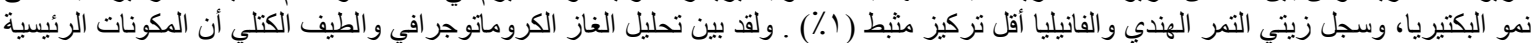

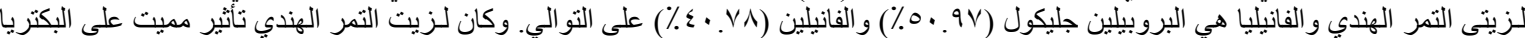

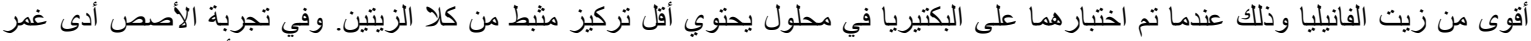

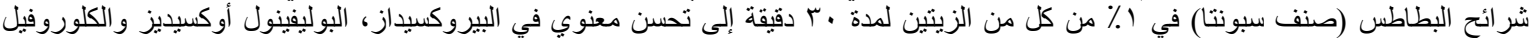

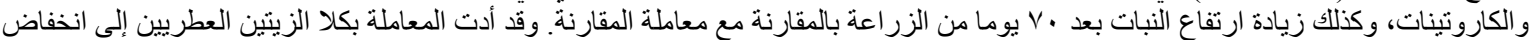

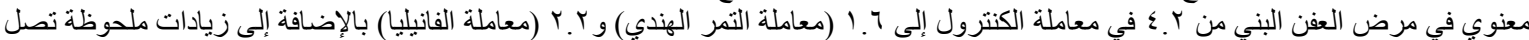

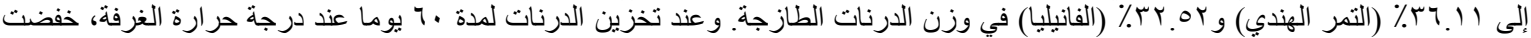

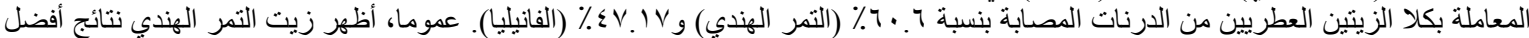

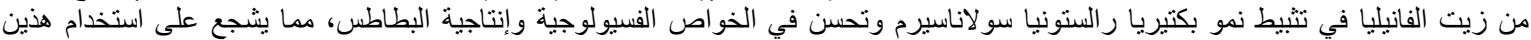

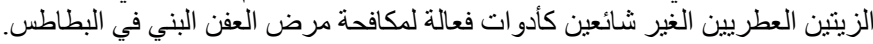

